Buana Sains Vol 19 No 1: 17 - 24, 2019

\title{
PENGGUNAAN BIOCHAR DIPERKAYA NITROGEN PADA TANAMAN JAGUNG
}

\author{
Titik Islami
}

Fakultas Pertanian, Universitas Brawijaya

\begin{abstract}
Most agricultural land in lndonesia has a low organic matter content, and this is due to the fast decomposition rate of soil organic matter. The rapid decomposition of soil organic matter causes low soil fertility. To maintain high agricultural yields, it is necessary to add soil organic matter repeatedly in each planting season with a high dose ( $>10$ tons / ha). Farmers considered that the addition of high-dose organic matter to their agricultural land is not economical and difficult to do. Therefore, soil organic matters which is resistant to decomposition is needed, so that it can last longer in the soil. One of the recalcitrant soil organic matter is biochar, and many studies have shown that biochar can reduce the need for nitrogen in the next cropping season. Previous research has shown that biochar can be enriched with nitrogen as an organic fertilizer. This study aims to study the effect of biochar which has enriched nitrogen from ammonium on the growth and yield of maize. The study was conducted in Landungsari Village, Malang City in July to December 2018. This study used a randomized block design (RBD) with combinations of 5 treatments and 5 replications. The treatments in this study were: B0 (control); B1 (nitrogen fertilizer $90 \mathrm{~kg} / \mathrm{ha}$ ); B2 (nitrogen fertilizer $90 \mathrm{~kg} / \mathrm{ha}+$ biochar); B3 (biochar enriched with ammonium sulfate 4 tons / ha); B4 (manure 4 tons / ha + nitrogen f'ertilizer $90 \mathrm{~kg} / \mathrm{ha}$ ). The results of the study showed that biochar enriched with ammonium sulfate at a dose of 4 tons / ha increased the growth and yield of maize. Biochar enriched with ammonium sulfate shows the ability to hold nitrogen which can then be released in the soil in the form of $\mathrm{NH} 4+$ to be absorbed by plants.
\end{abstract}

Keywords: Biochar; Maize; Nitrogen efficiency; Organic fertilizer; Soil amandement.

\section{Pendahuluan}

Sebagai akibat laju dekomposisi dan demineralisasi bahan organik pada tanah di daerah tropis basah berjalan sangat cepat (Lehman et al,. 2003). Hal ini mengakibatkan sebagian besar tanah pertanian di daerah ini mempunyai kandungan bahan organik sangat rendah. Hal ini juga terjadi di Indonesia (Islami et al.,2011a). Pada hal bahan organik mempunyai peran sangat penting di dalam tanah, mulai sebagai sumber hara tanaman, sumber energi bagi organisme tanah, penyangga kesuburan kimia tanah, dan bahan semen dalam pembentukan dan pemantapan struktur tanah (Braddy \& Neil, 2002). Akibatnya sebagian besar lahan pertanian di lndonesia mempunyai kesuburan dan produktivitas rendah, dan tidak berlanjut.

Dengan kenyataan bahwa salah satu penyebab utama masalah kesuburan tanah adalah rendahnya kandungan bahan organik tanah, maka strategi untuk mendapatkan produktivitas tinggi dan 
berlanjut pada lahan pertanian adalah dengan meningkatan kandungan bahan organik, baik melalui penambahan bahan organik dari luar, maupun dengan pengaturan pola tanam (Islami et al.,2011a). Untuk mendapatkan hasil yang baik pemberian bahan organic harus diberikan pada dosis yang tinggi, pada umumnya lebih dari 10 ton/ha. Pada fihak lain, pada kondisi iklim kopis basah seperti halnya di Indonesia, pelapukan bahan organik berjalan sangat cepat (Masulili et al., 2010). Oleh karena itu untuk mempertahankan hasil yang tinggi pemberian bahan organik harus diberikan secara berulang setiap musim (Islami et al., 2011b; Sukartono et al., 2011b). Padahal, ketersediaan dan akses petani terhadap bahan organic sangat terbatas. Jadi, disamping kurang ekonomis, petani kesulitan untuk dapat melakukan pemberian bahan organik pada tanamannya. Oleh karena itu, diperlukan suatu bentuk bahan organik yang dapat bertahan lama di dalam tanah, sehingga mampu memberikan manfaat positif kepada pertumbuhan tanaman dalam jangka waktu yang lebih lama.

Akhir-akhir ini, dengan memperhatikan stabilitas hasil tanaman pertanian di tanah "terra Preta" di Amazon, para pakar pertanian mulai melirik menggunaan arang (yang kemudian dikenal dengan istilah biochar) sebagai sumber bahan organik untuk pertanian (Lehman et al., 2003). Berbagai hasil penelitian telah menunjukkan bahwa penggunaan biochar dapat memperbaiki kesuburan tanah, sekaligus meningkatkan hasil tanaman (Chan et al., 2007; Yamato et al.,2006).

Penelitian yang dilakukan oleh anggota kelompok peneliti di Pusat Studi Tanaman Ubi-Ubian Universitas Brawijaya (PSTU-UB) dan International Research Centre for The Management of Degraded and Mining Lands (IRC-
MEDMIND) sejak tahun 2008 juga menunjukkan hasil yang menjanjikan (Masulili et al., 2010; Islami et al., 2011b; 2011c; Sukartono et al.,2011a; 2011b; Widowati et al.,2011a; 2012; Sukartono et al., 2012; Utomo \& Islami, 2013a; 2013b; Nur et al., 2014a; 2014b; Islami et al.,2015). Masulili et al., (2010) menunjukkan bahwa pemberian biochar dari selkam padi dapat memperbaiki kesuburan tanah sulfat asam di Kalimantan Barat, terutama adanya perbaikan pH dan Kapasitas Tukar Kation (KTK) Tanah, dan sekaligus memperbaiki pertumbuhan tanaman padi. lslami et al., (2011b; 2011c) membuktikan penggunaan biochar dari pupuk kandang dan batang ubikayu, seperti halnya pupuk kandang, dapat memperbaiki kesuburan tanah terdegradasi dan sekaligus meningkatkan hasil tanaman, pada pola tanam tumpangsari berbasis tanaman ubikayu.

Hasil yang sama juga diperoleh pada tanaman ubikayu tunggal (Islami et al., 2013b). Sukartono et al., (2011b; 2012) membuktikan bahwa pemberian biochar dari kotoran sapi dan tempurung kelapa dapat memperbaiki sifat fisik tanah lempung berpasir di Lombok, terutama struktur dan kemampuan menyimpan air.

Pengaruh positif ini berlanjut pada peningkatan hasil tanaman jagung, baik yang ditanam pada musim hujan maupun musim kemarau. Adanya perbaikan kesuburan tanah alkalis karena pemberian biochar juga sudah dibuktikan oleh Nur et al., (2014a; 2014b). Utomo dan Islami (2013) dan Islami et al., (2017) juga menunjukkan bahwa penggunaan biochar dapat meningkatkan hasil dan rendemen tanaman tebu. Penggunaan biochar untuk pertanian mempunyai keuntungan lebih, karena pengaruh positif pemberian biochar masih bertahan untuk tanaman berikutnya 
(Islami et al., 2011b; Sukartono et al.,2011b; Widowati et al,, 2017a), bahkan sampai tahun keempat (Islami et al; 2015). Padahal untuk mempertahankan pengaruh positifnya, pupuk kandang harus diberikan pada setiap musim tanam. Widowati et al., (2012), Utomo dan Islami (2013) menunjukkan penggunaan biochar dapat mengurangi kebutuhan pupuk nitrogen pada berikutnya. Jadi pemberian biochar dapat meningkatkan efisiensi pemakaian pupuk nitrogen, sekaligus meningkatkan pendapatan petani. Hal ini disebabkan karena penggunaan biochar dapat mengurangi kehilangan unsure hara, terutama nitrogen (dalam bentuk $\mathrm{NH}_{4}{ }^{+}$) dan mungkin kalium. Hal ini disebabkan karena penggunaan biochar dapat meningkatkan KTK tanah (Liang et al.,2006) dan dengan demikian dapat meningkatkan jerapan unsurehara pada kompleks jerapan. Di samping itu, hasil penelitian Widowati et al., (2011) menunjukkan bahwa penggunaan biochar menyebabkan unsur nitrogen yang telah dibebaskan dari pupuk tetap berada dalam bentuk $\mathrm{NH}_{4}{ }^{+}$, dan hal ini akan dapat menurunkan nitrifikasi dan kehilangan hara karena pencucian.

Terjadinya penurunan kehilangan nitrogen karena biochar juga berakibat pada terjadinya peningkatan kandungan nitrogen di dalam tanah yang diberi biochar. Dengan demikian adalah wajar jika kebutuhan pupuk nitrogen pada tanah yang pemah diberi biochar lebih kecil dibandingkan dengan dengan tanah tanpa biochar sebagaimana telah dibuktikan oleh Widowati et al. (2012) dan utomo \& Islami, 2013a). Hasil penelitian Wisnubroto et al. (2011) dan Utomo et al. (2017) telah menunjukkan potensi dari biochar yang diperkaya nitrogen sebagai pupuk organic pada tanah tropis di lndonesia.

\section{Metode Penelitian}

Penelitian ini dilakukan di desa Landungsari, Kecamatan Lowokwaru, Kotamadya Malang, dimulai pada bulan Juli 2018 sampai dengan Desember 2018. Bahan yang digunakan dalam penelitian ini adalah Biochar yang dibuat dari bahan dasar tongkol Jagung. Biochar ini diperkaya ammonium sulfat untuk meningkatkan unsure $\mathrm{N}$ di dalam Biochar. Metode Pengkayaan Biochar dilakukan berdasarkan hasil penelitian Wisnubroto et al (2017).

Penelitian dilakukan dengan
menggunakan
Kelompok (RAK), dengan ulangan sebanyak 5 kali ulangan. Perlakuan yang diuji dalam penelitian ini adalah:

1. $\mathrm{B} 0=$ Kontrol, tanpa pupuk $\mathrm{N}$

2. $\mathrm{B} 1=$ Diberi pupuk $\mathrm{N}$ dengan dosis $90 \mathrm{~kg} \mathrm{~N} / \mathrm{ha}$

3. $\mathrm{B} 2=$ Diberi pupuk $\mathrm{N}$ dengan dosis $90 \mathrm{~kg} \mathrm{~N} / \mathrm{ha}+$ BIochar dengan dosis $4 \mathrm{t} / \mathrm{ha}$

4. B3= Diberi Biochar deperkaya Ammonuim 4t/ha

5. B4= Diberi pupuk kandang 4t/ha dan $90 \mathrm{~kg} \mathrm{~N} / \mathrm{ha}$

Variabel pengukuran dari penelitian ini adalah pertumbuhan tanaman jagung, meliputi: tinggi tanaman umur 15, 30, 60 hari setelah tanam (HST), jumlah daun waktu panen, biomassa bagian vegetative waktu panen, hasil tanaman, biomassa total, jumlah biji per tongkol, berat 100 biji, indeks panen.

\section{Pembuatan dan Pengkayaan Biochar}

Pembuatan biochar dilakukan di laboratorium bioenergy Universitas Tribhuwana Tunggadewi, Malang. Pembuatan Biochar dilaksanakan tanggal 18 April 2016. Untuk keperluan ini diperlukan bahan baku tongkol jagung. Pembuatan biochar dilakukan dengan 
metoda pyrolisis pada temperature $400^{\circ} \mathrm{C}$ sebagaimana oleh Masulili et al (2010).

Analisis yang dilakukan pada biochar yang dihasilkan meliputi kadar air, $\mathrm{pH}$, kandungan bahan C-organik, kandungan nitrogen $(\mathrm{N})$, posfor $(\mathrm{P})$ dan Kalium (K). kandungan bahan organic ditentukan dengan metoda Walkley \& Black, kandungan air, $\mathrm{N}, \mathrm{P}$ dan $\mathrm{K}$ dilakukan dengan metoda analisis pupuk yang digunakan oleh Balai Penelitian Tanah (Sulaeman, 2005). Biochar yang dihasilkan dihaluskan dan diayak dengan lolos ayakan diameter 2,0 $\mathrm{mm}$, kemudian diperkaya dengan nitrogen yang berasal dari Amoniumsulfat.

Percobaan pengkayaan Biochar dilakukan di Laboratorium Ilmu Tanah Uiversitas Brawijaya, Malang. Pengkyaan biochar dengan Amoniumsulfat dilakukan denhan metode yang dikembangkan oleh Taghizadesh-Tossi et al. (2012). Untuk keperluan ini biochar dilarutkan dalam botol kedap udara, ditutup dengan penutup botol dengan bahan karet kemudian disuntik dengan larutan ammonium sulfat. Campuran larutan dalam botol ini kemudian didiamkan selama satu minggu, dan selanjutnya dikeringkan pada temperature kamar. Setelah kering, kandungan nitrogen pada biochar yang telah diperkaya tersebut dianalisis dengan metoda kejhdahl. Hasil analisis dari biochar tersaji pada tabel 1 dimana dapat terlihat perbandingan antara kandungan biochar dengan kandungan biochar yang diperkaya..

Tabel 1. Karakteristik biochar dan biochar diperkaya $\mathrm{N}$ berbahan baku tongkol jagung

\begin{tabular}{lll}
\hline Karakteristik biochar & Biochar & Biochar diperkaya \\
\hline Kandungan air $(\% \mathrm{w} / \mathrm{w})$ & 5,86 & 6,02 \\
$\mathrm{pH}-\mathrm{H}_{2} \mathrm{O}$ & 8,24 & 7,56 \\
$\mathrm{C}(\%)$ & 47,06 & 48,37 \\
$\mathrm{~N}(\%)$ & 0,09 & 2,33 \\
$\mathrm{P}(\%)$ & 0,15 & 0,15 \\
$\mathrm{C} / \mathrm{N}$ & 52,28 & 20,75 \\
$\mathrm{~K}(\%)$ & 0,78 & 0,74 \\
$\mathrm{Ca}(\%)$ & 0,46 & 0,51 \\
$\mathrm{Na}(\%)$ & 0,12 & 0,09 \\
$\mathrm{Mg}(\%)$ & 0,16 & 0,16 \\
$\mathrm{Kapasitas}$ Tukar Kation $\left(\mathrm{cmol} \mathrm{kg}^{-1}\right)$ & 14,75 & 14,26 \\
\hline
\end{tabular}


Titik Islami/ Buana Sains Vol 19 No $1: 17-24$

\section{Hasil dan Pembahasan}

Tabel 2. Pengaruh penggunaan biochar diperkaya nitrogen pada tanaman jagung terhadap rerata tinggi tanaman

\begin{tabular}{|c|c|c|c|c|}
\hline \multirow{2}{*}{ Perlakuan } & \multicolumn{4}{|c|}{ Tinggi tanaman $(\mathrm{cm})$ Pada umur (Hst) } \\
\hline & 15 & 30 & 60 & Panen \\
\hline Kontrol, tanpa pupuk N (B0) & $20,25 \mathrm{a}$ & $39,00 \mathrm{a}$ & $165,25 \mathrm{a}$ & $170,25 \mathrm{a}$ \\
\hline Pupuk N dosis $90 \mathrm{~kg} \mathrm{~N} / \mathrm{ha}(\mathrm{B} 1)$ & $20,50 \mathrm{a}$ & $46,00 \mathrm{~b}$ & $182,25 b$ & $198,50 \mathrm{~b}$ \\
\hline Pupuk N dosis $90 \mathrm{~kg} \mathrm{~N} / \mathrm{ha}+$ Biochar 4t/ha (B2) & $21,50 \mathrm{a}$ & $46,25 \mathrm{bc}$ & $188,75 b$ & $203,75 b c$ \\
\hline Biochar diperkaya N 4t/ha (B3) & $22,00 \mathrm{a}$ & $50,75 \mathrm{c}$ & $198,50 \mathrm{c}$ & $206,25 c$ \\
\hline Pupuk kandang 4t/ha $+90 \mathrm{~kg} \mathrm{~N} / \mathrm{ha}(\mathrm{B} 4)$ & $20,25 \mathrm{a}$ & $44,50 \mathrm{~b}$ & $189,00 \mathrm{~b}$ & $204,75 c$ \\
\hline
\end{tabular}

Keterangan : Bilangan yang didampingi huruf yang sama tidak berbeda nyata

Dari Tabel 2 dapat dilihat bahwa, parameter tinggi tanaman umur 15 hst tidak berbeda nyata untuk semua perlakuan. Pada umur 30 hst, perlakuan kontrol (B0) menghasilkan tinggi tanaman yang terendah, sedangkan perlakuan pupuk N 90kg/ha (B1), perlakuan pupuk N 90kg/ha + Biochar 4t/ha (B2) dan perlakuan pupuk kandang 4t/ha $+90 \mathrm{~kg} \mathrm{~N} / \mathrm{ha}$ (B4) tidak berbeda nyata. Perlakuan pupuk N 90kg/ha + Biochar 4t/ha (B2) tidak berbeda nyata dengan perlakuan biochar yang diperkaya $\mathrm{N}$ 4t/ha (B3). Pada saat umur 60 hst perlakuan kontrol (B0) menghasilkan tinggi tanaman terendah, sedangkan perlakuan biochar diperkaya $\mathrm{N}$ 4t/ha (B3) menghasilkan tinggi tanaman tertinggi. Perlakuan pupuk $90 \mathrm{~kg} \mathrm{~N} / \mathrm{ha}$ (B1); perlakuan pupuk 90kg N/ha + Biochar 4t/ha (B2) dan pupuk kandang 4t/ha $+90 \mathrm{~kg} \mathrm{~N} /$ ha tidak berbeda nyata.
Pada saat panen perlakuan kontrol menghasilkan tinggi tanaman yang terendah, sedangkan perlakuan dosis N 90kg/ha (B1) dan perlakuan pupuk N 90kg/ha + Biochar 4t/ha (B2) tidak berbeda nyata. Perlakuan biochar diperkaya $\mathrm{N} \mathrm{4t/ha} \mathrm{(B3)} \mathrm{menghasilkan}$ tinggi tanaman yang lebih tinggi dibandingkan dengan perlakuan B2 dan B4 meskipun tidak berbeda nyata.

Pada tabel 3 terlihat bahwa parameter jumlah daun tidak berbeda nyata untuk semua perlakuan. Parameter biomassa vegetatif pada saat panen menunjukkan perlakuan biochar yang diperkaya $N$ (B3) dan perlakuan pupuk kandang dan $90 \mathrm{~kg} \mathrm{~N} / \mathrm{ha}$ (B4) tidak berbeda nyata dan lebih tinggi dari perlakuan lainnya. Sedangkan perlakuan kontrol tanpa pupuk N (B0) menghasilkan biomassa vegetatif yang paling rendah.

Tabel 3. Pengaruh penggunaan biochar diperkaya nitrogen pada tanaman jagung terhadap jumlah daun dan biomassa vegetatif pada saat panen

\begin{tabular}{lll}
\hline Perlakuan & Jumlah daun & $\begin{array}{l}\text { Biomassa vegetatif } \\
\text { (Kg/tanaman) }\end{array}$ \\
\hline Kontrol, tanpa pupuk N (B0) & $11,8 \mathrm{a}$ & $2,57 \mathrm{a}$ \\
Pupuk N dosis 90kg N/ha (B1) & $11,8 \mathrm{a}$ & $4,56 \mathrm{~b}$ \\
Pupuk N dosis 90kg N/ha + Biochar 4t/ha (B2) & $12,6 \mathrm{a}$ & $5,23 \mathrm{~b}$ \\
Biochar diperkaya N 4t/ha (B3) & $13,0 \mathrm{a}$ & $6,23 \mathrm{c}$ \\
Pupuk kandang 4t/ha $+90 \mathrm{~kg} \mathrm{~N} / \mathrm{ha}(\mathrm{B} 4)$ & $12,8 \mathrm{a}$ & $6,13 \mathrm{c}$ \\
\hline
\end{tabular}

Keterangan : Bilangan yang didampingi huruf yang sama tidak berbeda nyata 
Titik Islami/ Buana Sains Vol 19 No 1 : 17-24

Tabel 4. Pengaruh penggunaan biochar diperkaya nitrogen pada tanaman jagung terhadap rerata panjang tongkol, diameter tongkol, jumlah biji per tongkol dan berat 100 biji

\begin{tabular}{lcccc}
\hline \multicolumn{1}{c}{ Perlakuan } & $\begin{array}{c}\text { Panjang } \\
\text { tongkol } \\
(\mathrm{cm})\end{array}$ & $\begin{array}{c}\text { Diameter } \\
\text { tongkol } \\
(\mathrm{cm})\end{array}$ & $\begin{array}{c}\text { Jumlah } \\
\text { biji/tongkol }\end{array}$ & $\begin{array}{c}\text { Berat } \\
100 \mathrm{biji} \\
(\mathrm{g})\end{array}$ \\
\hline Kontrol, tanpa pupuk N (B0) & $12,26 \mathrm{a}$ & $3,56 \mathrm{a}$ & $227,7 \mathrm{a}$ & $30,86 \mathrm{a}$ \\
Pupuk N 90kg N/ha (B1) & $18,75 \mathrm{~b}$ & $4,58 \mathrm{~b}$ & $349,7 \mathrm{~b}$ & $33,23 \mathrm{~b}$ \\
Pupuk N 90kg N/ha + Biochar 4t/ha (B2) & $19,50 \mathrm{~b}$ & $4,92 \mathrm{~b}$ & $372,7 \mathrm{c}$ & $36,62 \mathrm{c}$ \\
Biochar diperkaya N 4t/ha (B3) & $20,26 \mathrm{~b}$ & $4,82 \mathrm{~b}$ & $415,5 \mathrm{~d}$ & $38,36 \mathrm{c}$ \\
Pupuk kandang 4t/ha + 90 kg N/ha (B4) & $19,60 \mathrm{~b}$ & $4,90 \mathrm{~b}$ & $416,0 \mathrm{~d}$ & $36,77 \mathrm{c}$ \\
\hline
\end{tabular}

Keterangan : Bilangan yang didampingi huruf yang sama tidak berlaku nyata

Tabel 5. Pengaruh penggunaan biochar diperkaya nitrogen pada tanaman jagung terhadap rerata hasil biji/ha dan indeks panen

\begin{tabular}{lcc}
\hline Perlakuan & Hasil biji t ha-1 & Indeks panen \\
\hline Kontrol, tanpa pupuk N (B0) & $2,72 \mathrm{a}$ & $0,52 \mathrm{~b}$ \\
Pupuk N 90kg N/ha (B1) & $4,58 \mathrm{~b}$ & $0,50 \mathrm{ab}$ \\
Pupuk N 90kg N/ha + Biochar 4t/ha (B2) & $5,36 \mathrm{c}$ & $0,50 \mathrm{ab}$ \\
Biochar diperkaya N 4t/ha (B3) & $6,26 \mathrm{~d}$ & $0,50 \mathrm{ab}$ \\
Pupuk kandang 4t/ha $+90 \mathrm{~kg} \mathrm{~N} / \mathrm{ha}$ (B4) & $5,99 \mathrm{~cd}$ & $0,49 \mathrm{a}$ \\
\hline
\end{tabular}

Keterangan : Bilangan yang didampingi huruf yang sama tidak berbeda nyata

Komponen hasil yang meliputi panjang tongkol menunjukkan perlakuan kontrol (B0) menghasilkan panjang tongkol terkecil sedangkan perlakuan lainnya B1, B2, B3 dan B4 tidak berbeda nyata. Pada diameter tongkol juga menunjukkan hal yang sama. Pada jumlah biji per tongkol perlakuan kontrol (B0) menunjukkan jumlah biji terendah sedangkan perlakuan B3 dan B4 tidak berbeda nyata namun lebih banyak menghasilkan jumlah biji per tongkol dibandingkan dengan perlakuan B1 dan B2. Pada parameter berat $100 \mathrm{~g}$ biji perlakuan kontrol menghasilkan berat terendah, sedangkan perlakuan B1 lebih tinggi dari B0 dan berbeda nyata. Perlakuan B2, B3 dan B4 tidak berbeda nyata.

Pada parameter hasil biji per ha terlihat bahwa perlakuan B3 dan B4 tidak berbeda nyata dan lebih tinggi dari perlakuan lainnya, perlakuan B2 tidak berbeda dengan perlakuan B4 sedangkan perlakuan kontrol menghasilkan biji per ha yang terendah. Pada indeks panen perlakuan kontrol (B0) berbeda dengan perlakuan B4 namun tidak berbeda dengan perlakuan B1, B2 dan B3, sedangkan perlakuan B4 berbeda dengan perlakuan B0.

Dari pengamatan didapatkan hasil bahwa perlakuan kontrol menunjukkan pertumbuhan dan hasil yang rendah, hal ini dapat dijelaskan bahwa tanaman jagung membutuhkan nutrisi (unsur hara) yang cukup bagi pertumbuhannya, sehingga karena tidak diberi penambahan pupuk kandang, puouk $\mathrm{N}$ maupun biochar maka pertumbuhannya terhambat. Perlakuan pupuk N 90kg/ha menunjukkan hasil yang hampir sama dengan perlakuan kontrol meskipun cenderung meningkat namun pertumbuhan dan hasilnya kurang optimal. Hal ini disebabkan 
karena umumnya tanah-tanah pertanian di Indonesia mempunyai kandungan bahan organik yang rendah (Islami, et al 2011a). Padahal bahan organik mempunyai peran penting di dalam tanah, mulai dari sebagai sumber hara tanaman, sumber energi bagi organisme. Akibatnya pupuk N 90kg/ha yang diberikan tidak mampu mendukung pertumbuhan dan hasil tanaman jagung. Pada perlakuan Biochar 4t/ha dan pupuk $\mathrm{N} 90 \mathrm{~kg} / \mathrm{ha}$ pertumbuhan tanaman dan hasilnya dapat meningkat, hal ini disebabkan karena nutrisi yang dibutuhkan tanaman mencukupi, apalagi dengan adanya tambahan Biochar 4t/ha dapat membantu dalam perbaikan sifat fisik tanah, sehingga serapan unsur hara bagi tanaman berjalan dengan baik.

$\mathrm{Hal}$ ini sesuai dengan hasil penelitian Sukartono et al (2012) yang melakukan penelitian di Lombok Utara. Pada perlakuan biochar yang diperkaya Nitrogen, mempunyai fungsi ganda, di samping menambah hara $(\mathrm{N})$ biochar

\section{Kesimpulan}

Dari hasil penelitian dapat disimpulkan bahwa perlakuan biochar yang diperkaya nitrogen dapat meningkatkan pertumbuhan tanaman (tinggi tanaman, jumlah daun dan biomassa vegetatif) dan hasil tanaman jagung (panjang tongkol, diameter tongkol, jumlah biji per tongkol, berat 100 biji dan hasil biji per ha).

\section{Daftar Pustaka}

Braddy, N.C. \& Weil, R.R. 2002. The Nature and Properties of Soils. 13th ed. Prentice Hall Ltd. New York.

Islami, T., Guritno, B. \& Utomo, W.H. 2015. Farmyard manure biochar for sustainable cassava production production on degraded lands of juga berfungsi meningkatkan KTK dan dapat menyerap $\mathrm{NH} 4+$ dari unsur $\mathrm{N}$ yang ditambahkan dan tersedia bagi tanaman jagung. Liang et al (2006) menjelaskan kenaikan hasil tanaman dengan penggunaan biochar mampu memperkecil kehilangan hara karena pencucian, sehingga penggunaan biochar dapat meningkatkan efektifitas pemupukan. Pernyataan tersebut didukung oleh penelitian Widowati et al (2011) yang menunjukkan bahwa kebutuhan pupuk pada tanaman jagung pada tanah yang diberi biochar lebih rendah dibandingkan dengan tanaman jagung yang tidak diberi biochar. Karena sifat biochar yang tahan terhadap pelapukan maka penggunaan biochar dapat mengurangi penggunaan pupuk Nitrogen pada penanaman berikutnya (Utomo dan Islami, 2013). Secara keseluruhan perlakuan biochar yang diperkaya Nitrogen dapat meningkatkan pertumbuhan dan hasil tanaman jagung.

East Java, Indonesia. Proc. Of the Cassava Regional Workshop at Guangzhou, China: December 2012. CIAT Asia Office, Hanoi.

Islami, T., Guritno, B., Basuki, N. \& Suryanto, A. 2011b.Maize Yield and Associated Soil Quality Changes in Cassava + Maizeintercropping System After 3 Years of Biochar Application. J. Agric. Food. Tech., 1(7) 112-115

Islami, T., Guritno, B., Basuki, N. \& Suryanto, A. 2011c. Biochar for sustaining productivity of cassava based cropping systems in the degraded lands of East Java, Indonesia. Journal of Tropical Agriculture 49 (1-2) : 40-46

Islami, T., Utomo, W.H. \& Guritno, B. 2011a. Performance of cassava (Manihot esculenta Crants) based 
cropping systems and associated soil quality changes in the degraded tropical uplands of East Java, Indonesia. Journal of Tropical Agriculture 49 (1-2) : 31-39

Lehman, J., da Silva Jr.J.P., Steiner, C., Nehls, T., Zech, W. \& Glasser, B. 2003. Nutrient availability and leaching in an archaeological Anthrosol and a Ferralsol of the Central Amazon basin: fertilizer, manure and charcoal amendments. Plant and Soil, 249, 343-357.

Liang, B., Lehmann, J., Kinyangi, D., Grossman, J., O’Neill, B., Skjemstad, J.O., Thies, J., Luizao, F.J., Peterson, J., \& Neves, E.G. 2006. Black carbon increases cation exchange capacity in soils. Soil Sci. Soc. Am. J., 70, 1719-1730

Masulili, A.Utomo, W.H. \& Syekhfani, M.S. 2010. Rice husk biochar for rice based cropping system in acidic soils: The characteristics of rice husk biochar and its influence on the properties of acid sulfate soils and rice growth in West kalimantan, Indonesia. J. Of Agric. Sci. (Canada) 2:39-47

Nur, M.M., Utomo, W.H., Handayanto, E. \& Islami, T. 2014a. The Use of Biochar fortified compost on calcareous soil of East Nusa Tenggara, Indonesia: 1. Evolution of organic matter and nitrogen on composting of farm yard manure (FYM) and Siam weed (Chromolaena odorata L.) biomass added with biochar as a bulking agent. Advanced in Natural and Appl. Sci. 2014, 8: 175-182

Nur, M.M., Utomo, W.H., Handayanto, E. \& Islami, T. 2014b. The Use of Biochar fortified compost on calcareous soil of East Nusa
Tenggara, Indonesia: 2. Effect on the Yield of Maize (Zea Mays L) and Phosphate Absorption. AEJSA 2015, 8:105-111.

Sukartono, Utomo, W.H., Kusuma, Z. \& Nugroho, W.H. 2011b. Soil fertility status, nutrient uptake, and maize (Zea mays L.) yield following biochar and cattle manure application on sandy soils of Lombok, Indonesia. J. Of Tropical Agriculture 2011, 49:47-52

Utomo, W.H. \& Islami, T. 2013a. Nitrogen fertilizier requirement of maize (Zea mays L.) on biochartreated soil. Proc. Int Workshop on "Biochar for future food security:Learning from experiences and identifying rsearch priorities" IIRRI-CFORD, Bogor, Indonesia. May 2013

Utomo, W.H. \& Islami, T. 2013b.The use of biochar derived from sugarcane industry waste for increasing productivity of degraded land. Proc. Int. Workshop on Inovation in Resource Biomass Use:Biomass to Biochar. FFTC/ASPAC-ISRI, Hanoi. Vietnam. Sept. 2013

Widowati, Utomo, W.H., Guritno, B. \& Soehono, L.A. 2011. Effect of biochar on the release and loss of nitrogen from urea fertilization.J. Agric. Food. Tech. 2011, 1:127132

Wisnubroto, E.I., Utomo, W.H., \& Soelistyari, H.T. 2017. Biochar as a Carrier for Nitrogen Plant Nutrition: The Release of Nitrogen from biochar Enriched with Ammonium Sulfate and Nitrate Acid. International Journal of Applied Engineering Research, 12(6), 1035-1042. 